\title{
Consumers' Perceived Vulnerability on Food Access under Climate-Induced Disasters
}

\author{
Maria Rochelle G. Divinagracia \\ Conrado Benitez Institute for Business Education \\ Philippine Women's University \\ Philippines
}

\author{
Louie A. Divinagracia \\ eLearning Author in Basic and Advanced Agribusiness \\ Asian Productivity Organization
}

\begin{abstract}
A pattern of sequential and/or simultaneous responses to vulnerability to food access under climate-induced disasters builds up from minor adjustments such as diet changes to a major shift in livelihood. The study found that the gainfullyemployed respondents-households have taken actions in preparation to possible food inaccessibility under CIDs. The level of awareness on the impact of CIDs on food access and the respondents' role in the family are significantly related. Further study on the behavioral and psychological responses to other anticipated climate change impacts, especially those that represent "new" and unfamiliar hazards, is timely. A study on the integration of 'underlying causes' of vulnerability and adaptive capacity in CIDs impact assessments rather than only focusing on adaptive capacity and technical measures is recommended.
\end{abstract}

Keywords-food access; vulnerability; disaster; climate-induced disaster; CID

\section{INTRODUCTION}

Food access, along with availability, affordability, quality, and safety, is an aspect of food security. In its report in 2011, the Food and Agriculture Organization of the United Nations (FAO) stated that food security encompasses food nutrition as well [1]. Porter et al. reported that extreme climate changes that result to climate-induced disasters (e.g. drought, floods, and tropical storms) will reduce food production and supply [2]. This implies that food shortages can result into higher food prices, and affect the access of food to households with lower food purchasing capability. In poverty-stricken areas, households tend to allocate a bigger proportion of their meager income on food purchases. This has been documented in FAO [1]. Furthermore, Porter et al. indicated that both urban consumers and rural non-farming households will be vulnerable unless the latter receives timely wage increases [2].

\section{Climate-Induced HaZARDS AND Disasters}

Climate-induced hazards are both natural and anthropogenic. Storms such as tropical cyclones or typhoons are classified as meteorological, floods are hydrological, droughts are climatological, and landslides are geophysical. Citing information from the Emergency Event Database of the Centre for Research on the Epidemiology of Disasters (CREDEM-DAT), 19. Thomas, Albert, and Perez mentioned that there is a rise in the occurrence of natural disasters [3]. Using the CRED-EM-DAT global database of relatively intense natural disasters, figures showed that those arising from hydrological and meteorological hazards accounted for twothirds of intense natural disasters for the past four decades, years 1971 to 2010. Moreover, these hazards contributed to about $70 \%$ of the increase in intense natural disasters between the 1971-1980 period, and that of the 2001-2010 timeframe. The Asia-Pacific rim accounted for about half of both the frequency and the percentage increase of intense natural disasters for the time periods indicated above. In the Philippines, more than $80 \%$ of the intense natural disasters originated from hydrological and meteorological hazards from 1971 to 2010, and the percentage increase more than doubled. In a continuing study, Thomas and Lopez acknowledged that the number of Category 5 storms tripled between 1980 and 2008 globally [4].

Disasters originating from climate-induced hazards occur if humans who are exposed to these are severely affected, resulting into great damage and suffering, and their communities are declared under a state of calamity. Kim mentioned that the poor, with their low adaptive capacity, are more vulnerable [5]. Their plight is exacerbated if they reside or continuously operate in hazard-prone areas. Thomas, Albert, and Perez clarified that adaptive capacity is associated with "the maintenance of certain structures and functions despite disturbances caused by a disaster," and is different from the concept of resilience ${ }^{1}[3]$.

Thomas and Lopez likewise said that with over 100 million individuals worldwide affected by climate-induced hazards in 2014 compared to less than 50 million in the 1990s, the multidimensionality of humans' vulnerability to climateinduced disasters has to be understood [4]. Ali said that vulnerability has three dimensions, namely, exposure to potential hazards, sensitivity to hazards, and capacity to respond [6]. Exposure and sensitivity to hazards defines the vulnerability context whereas potential impacts are defined as the interaction of the vulnerability context with the capacity to respond. Other than the mitigation of environmental degradation and the existence of a well-designed, organized and implemented disaster risk management plan at the local levels, demographic and socioeconomic factors have a

\footnotetext{
${ }^{1}$ Resilience is viewed as the ability of affected individuals, their households and communities to recover and return to their pre-disaster conditions after a disaster.
} 
significant role as well. For example, individuals and households with decent income levels, higher educational attainment, and literacy are associated with better adaptive capacity.

\section{SOCIAL VULNERABILITY ASSESSMENT}

Füssel differentiates vulnerability into social vulnerability (including socioeconomics); and biophysical or natural vulnerability [7]. The former is driven by the social system's resources, structures and processes. Socioeconomic drivers can be internal (e.g. household income, information access, social networks), and external (e.g. domestic policies, globalization). It was empathized that vulnerability assessments between natural hazards and climate-induced hazards are to be treated differently. Climate-induced hazards, for example, are associated with bigger uncertainties and long-term heterogeneous global changes; and involve human interferences.

Dow defines social vulnerability as "the differential capacity of groups and individuals to deal with hazards, based on their positions within physical and social worlds" [8]. In the past, indicators were categorized into 2 groups, namely, individual level variables; and community-level variables (e.g. population growth, infrastructure quality). Although no universally-accepted set of indicators are in used, Cutter, Boruff, and Shirley identified age, gender, race, and socioeconomic status are generally applied [9]. Other studies cited by Katic [10] had alternative ways of categorizing the indicators such as demographics (e.g. population growth rate, $\%$ of population under 6 years of age, \% of population over 65 years of age); economic (e.g. employment levels); and living conditions (e.g. housing standards, availability of sewage disposal, access to medical facilities).

Lundgren and Jonsson presented a summary of indexes/frameworks that was used in social vulnerability assessment [11]. These included, among others, the Social Vulnerability Index (SoVI) of Cutter, Boruff, and Shirley [9], Disaster Resilience of Place (DROP) of Cutter et al. (2008), and the Socio-economic Vulnerability Index (SeVI) and Build Environment Vulnerability Index (BEVI) of Holand et al. (2011). Katic [10] used a Comparable Social Vulnerability Profiling (CSVP) gathered from census data that contained the following indicators: age, gender, disability/dependency, income, minorities, and education. Each of these was considered to be independent and equally important. Thus, no weights were used ${ }^{2}$. The CSVP benefitted from the SoVI. Lundgren and Jonsson further indicated that attitudes and values of persons can be gathered (e.g. awareness of or preparation to climate-induced hazards) in addition to census data as these can provide supporting information on social vulnerability assessment [11].

Wu et al. developed indicators to assess social vulnerability in Taiwan using three (3) dimensions of susceptibility, resistance, and resilience [14]. The modified Delphi method was used to develop nine criteria and 26 indicators in the

2 There are other authors who argued the necessity of using weights which are driven by the experience and prior knowledge of stakeholders [12], [13]. evaluation. These indicators were measured from macroeconomic indicators such as population growth rate, population density, ratio of schools, ratio of government agencies, ratio of illiterate population, among others (Figure 1).

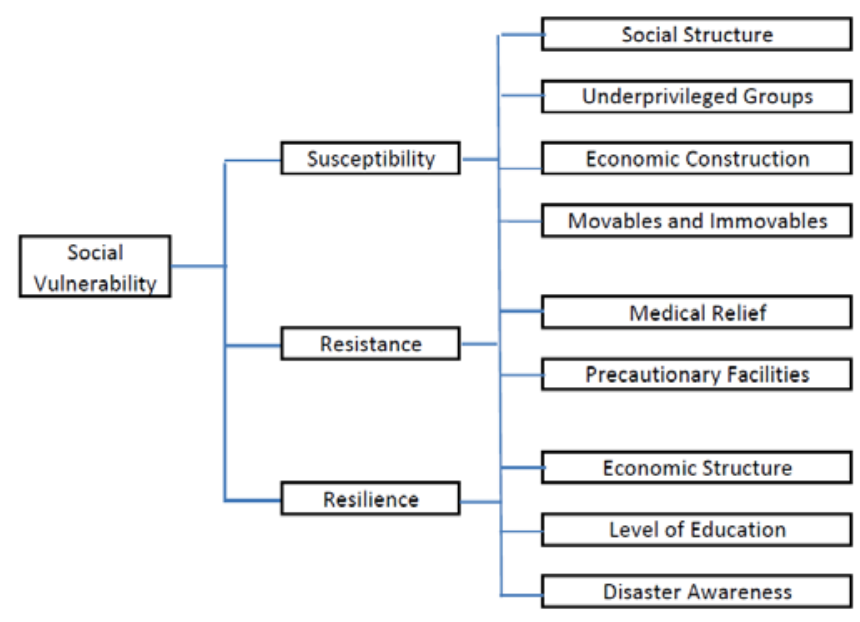

Fig. 1. Social Vulnerability Indicator Framework [14].

The vulnerability of people as well as organizations to crises and disasters stimulates the need for thinking of the most effective ways of managing them. Nevertheless, there is no single, universally adopted approach for crisis and disaster management that fits all countries and organizations [15], [16]. According to Pearson and Mitroff, crisis and disaster management is a multi-stage process that consists of six phases [17].

Risk

Crisis

Disaster

Fig. 2. Escalation of Events [18]

Shaluf likewise, stated that understanding and implementing crisis and disaster management best practices start with the recognition that crises and disasters consist of three stages, namely: (1) pre-crisis/disaster stage; (2) crisis/disaster stage; and (3) post-crisis/disaster stage [19]. Relating these phases, signal detection is a pre-disaster phase that aims to identify early warning signals that precede an event.

Preparation is a pre-disaster phase that aims to develop a state of readiness [20]. Crisis and disaster management best practice calls for preparation and prevention in the first place. Preparation/prevention involves preparing proactive and preventive measures in order to prevent potential risks to escalate into crises or disasters [15], [19]. Containment/damage limitation phase is concerned with the way an organization responds to an event when it occurs. The more severe the event is, the longer it takes to contain it and contain the damage. Short-term and long-term recovery phases aim to recover from the damage that has already occurred to the infrastructure and other elements of the organization and restore business functions [16], [21]. Learning is a post-disaster phase that aims to ensure that adequate reflection and critical examination of the lessons learned from experiencing an event 
are achieved. Learning from previous experiences facilitates the management of future incidents [17].

Vulnerability, in the context of this research, is a consequence of various potential elements for loss. One of which is food inaccessibility due to climate-induced disasters. Three distinct aspects of social vulnerability assessment were adopted from Wu's framework [14]. The first aspect is susceptibility, which is as the "degree to which a system is open, liable, or sensitive to climate stimuli". The second (resistance) and third aspects (resilience) relate to the societal response to and capability to recover from hazards. Timmerman (1981) defines vulnerability as "the measure of a system or part of a system's capacity to absorb and recover from the occurrence of a hazardous event”. This emphasizes that vulnerability is linked to individuals; and social resilience and resistance to hazards. Therefore, this exploratory study examines perceived vulnerability on food access under climateinduced disasters.

\section{METHODOLOGY}

The survey area is located in various localities in Palawan (Figures 3a and 3b). Palawan is one of the provinces in the Philippines frequently visited by local and foreign tourists for its beaches, reefs and forests. It has two (2) pronounced seasons, namely: dry (November to April) and wet (the rest of the year). Puerto Princesa gains an average of 1607 millimeters of rainfall per year or 133.9 millimeters per month (www.puerto-princesa.climatemps.com).

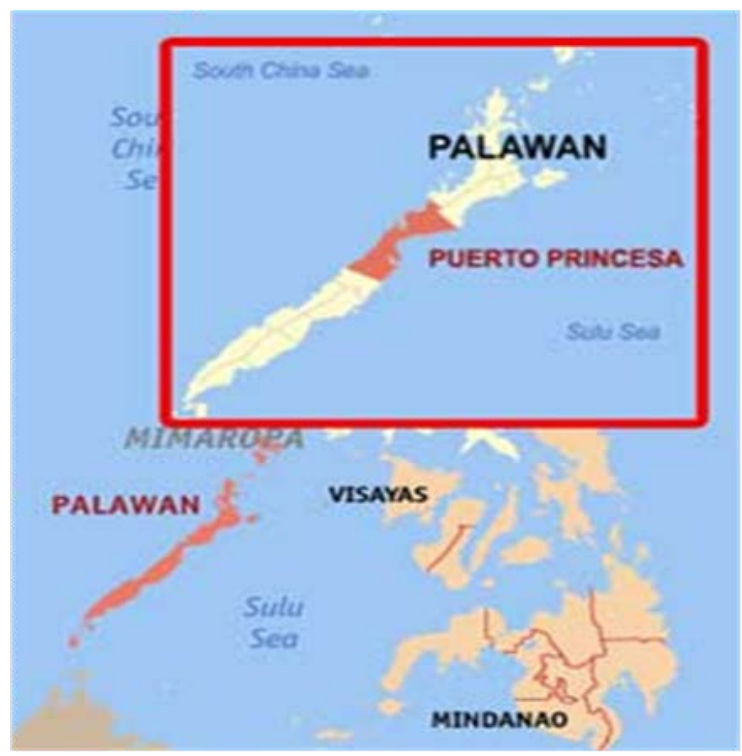

Fig. 3a. Map of Palawan (tourism-philippines.com/puerto-princesa/)

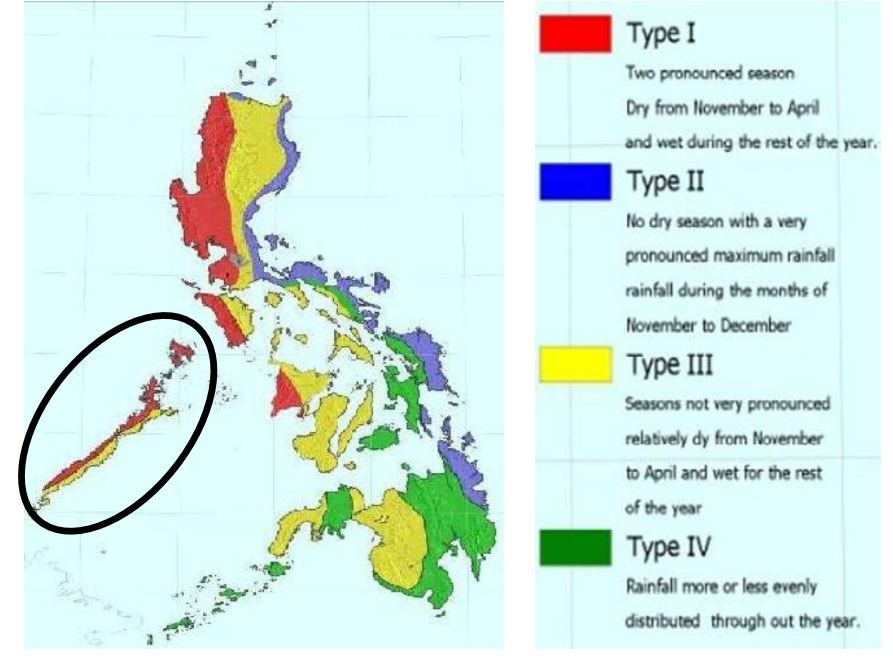

Fig. 3b. Rainfall Map of Palawan (www1.pagasa.dost.gov.ph)

Four hundred (400) gainfully-employed residents of Palawan were purposively selected as respondents of the study. However, only $93 \%$ response rate or 372 respondents. A pretested research instrument was administered and subsequently subjected to reliability test. The responses resulted to a Cronbach-alpha of 0.89 . Field editing was done to ensure that all items were completely answered. Descriptive statistics and appropriate statistical analysis were employed.

Rating scale and ranking were used to measure the perceived vulnerability on food access under climate-induced disasters. These measures were as follows:

- Level of awareness of impact of climate-induced disasters on food access;

- Association of physical conditions associated with climate-induced disasters;

- Extent of experience on physical conditions associated with climate-induced disasters;

- Impact on food access of physical conditions associated with climate-induced disasters;

- Level of susceptibility to food inaccessibility as a result of climate-induced disasters;

- $\quad$ Extent of preparation for possible food inaccessibility as a result of climate-induced disasters; and

- Actions taken in preparing for possible food inaccessibility as a result of climate-induced disasters.

Physical conditions associated with climate-induced disasters are tropical cyclones or typhoons, floods during the wet (rainy) season, drought during the dry season, and landslides during the rainy season.

Demographic characteristics of respondents such as age, gender, educational attainment, estimated average monthly household income, average household size, and role in the family, were gathered. 


\section{RESUltS AND DisCUSSION}

\section{A. Profile of Respondents}

Three hundred seventy-two (372) gainfully-employed residents of Palawan participated in the survey. Majority of these respondents are male, with an average age of 35 years old, have completed a college degree, at most an average monthly income of P50,000 (or approximately \$950), and an average household size of 4 .

The level of awareness on the impact of climate-induced disasters on food access is significantly associated with the respondents' role in the family $(r=0.71)$.

The responses revealed 4 typologies of respondents based from their role in the family. These typologies are as follows: (1) bread winner of the family; (2) helping the bread winner finance the food purchase of the family; (3) totally dependent on the bread winner for food supply; and (4) living alone and buys own food using personal earnings.

\section{B. Measures of Vulnerability to Food Access}

Table 1 shows the measures of vulnerability according to the role in the family. It is noticeable that 105 respondents who are the bread winner of the family are "very much aware" of the impact of climate-induced disasters (CIDs) on food access and perceived themselves to be very susceptible to food inaccessibility as a result of CIDs. They are also "prepared" for the possibility of food inaccessibility. Thus, the perceived actions to be taken in preparation for possible food inaccessibility are "storing processed food products" and "significantly reducing food waste."

"Storing processed food products" is perceived to be an effective action to be taken in preparation for food inaccessibility by both bread winner of the family, and family members who help the bread winner.

Eighty-seven (87) respondents who are living alone and purchased their food by themselves are also "very much aware" of the impact of climate-induced disasters (CIDs) on food access and perceived themselves as "susceptible" to food inaccessibility as a result of CIDs. They perceived that they are "somewhat prepared" for the possibility of food inaccessibility. "Shifting to healthier diet" is the action perceived to be taken by these respondents in preparation for possible food inaccessibility.
TABLE I.

MEASURES OF VULNERABILITY ACCORDING TO ROLE IN THE FAMILY

\begin{tabular}{|c|c|c|c|c|}
\hline \multirow[b]{2}{*}{ Measures } & \multicolumn{4}{|c|}{ Role in the Family } \\
\hline & BreadWinner & $\begin{array}{l}\text { Helping the } \\
\text { BreadWinner }\end{array}$ & $\begin{array}{c}\text { Totally Dependent } \\
\text { on BreadWinner }\end{array}$ & $\begin{array}{l}\text { Living Alone \& } \\
\text { Buying Own Food }\end{array}$ \\
\hline $\begin{array}{l}\text { Level of awareness of impact of } \\
\text { climate-induced disasters on } \\
\text { food access }\end{array}$ & very much aware & aware & aware & very much aware \\
\hline $\begin{array}{l}\text { Physical conditions associated } \\
\text { with climate-induced disasters }\end{array}$ & \multicolumn{4}{|c|}{$\begin{array}{l}\text { Increased frequency of tropical cyclones } \\
\text { Catastrophic floods during the rainy season }\end{array}$} \\
\hline $\begin{array}{l}\text { Extent of experience on physical } \\
\text { conditions associated with } \\
\text { climate-induced disasters }\end{array}$ & \multicolumn{4}{|c|}{ Regularly experiencing tropical cyclones \& floods during the rainy season } \\
\hline $\begin{array}{l}\text { Impact on food access of } \\
\text { physical conditions associated } \\
\text { with climate-induced disasters }\end{array}$ & highest impact & $\begin{array}{l}\text { moderate } \\
\text { impact }\end{array}$ & $\begin{array}{l}\text { having the most } \\
\text { minimal immpact }\end{array}$ & moderate impact \\
\hline $\begin{array}{l}\text { Level of susceptibility to food } \\
\text { inaccessibility as a result of } \\
\text { climate-induced disasters }\end{array}$ & very susceptible & very susceptible & susceptible & susceptible \\
\hline $\begin{array}{l}\text { Extent of preparation for } \\
\text { possible food inaccessibility as a } \\
\text { result of climate-induced } \\
\text { disasters }\end{array}$ & Prepared & Prepared & Prepared & $\begin{array}{c}\text { Somewhat } \\
\text { prepared }\end{array}$ \\
\hline $\begin{array}{l}\text { Actions taken in preparing for } \\
\text { possible food inaccessibility as a } \\
\text { result of climate-induced } \\
\text { disasters }\end{array}$ & $\begin{array}{l}\text { Storing processed } \\
\text { food products; } \\
\text { Significantly } \\
\text { reducing food } \\
\text { waste }\end{array}$ & $\begin{array}{c}\text { Storing } \\
\text { processed food } \\
\text { products }\end{array}$ & $\begin{array}{l}\text { Learning to eat the } \\
\text { right amount of } \\
\text { food; } \\
\text { Significantly } \\
\text { reducing food waste }\end{array}$ & $\begin{array}{c}\text { Shifting to } \\
\text { healthier diet }\end{array}$ \\
\hline
\end{tabular}

Ninety-one (91) respondents who are totally dependent on the bread winner of the family for food supply perceived that actions needed in preparation for food inaccessibility as a result of CIDs involve "learning to eat the right amount of food" and "significantly reducing food waste."

\section{Mitigating Risk Associated with Vulnerability}

Three distinct aspects of vulnerability assessment, namely: susceptibility, resistance, and resilience are important indicators that are associated to risk communication and mitigation.

The knowledge of vulnerability of respondents who have experienced an increased frequency of tropical cyclones and catastrophic floods are necessary to prioritize management ability to decrease risks and mitigate possible impacts. Mitigation of CIDs must consider both extreme conditions and social impacts that influence the engineering effectiveness of disaster prevention. Deployment of effective risk management strategies are expected to reduce the respondents' exposure to food inaccessibility. These include the following:

- Survey on public perception of the risk;

- Identification of risk information that people want;

- Explanation of various uncertainty factors;

- Collaboration and coordination with other credible sources of information;

- Emphasis on actions to monitor, manage, and reduce risk; and

- Planning and evaluation of risk messages and communication channels. 


\section{CONCLUSION}

The increased frequency of tropical cyclones, and floods during the rainy season have made the residents of Palawan vulnerable to food inaccessibility. The perceived actions to be taken in preparation for food inaccessibility during CIDs provide them with greater flexibility to reduce CIDs risks. It appears that the extent to which prior experience of CIDs and associated hazards impact on both level of awareness and preparedness to adapt warrants further exploration. With regard to adaptation in particular, it would seem that the relationship between prior experience and willingness to engage in proactive actions may depend on the nature of the hazard.

Adaptation to CIDs increasingly places emphasis on improving the capacity of governments and communities to address existing vulnerabilities to current climate variability. Echoing the recurring concerns of disaster management community is necessary for a more socially-informed approach to risk management.

From a climate change risk communication perspective, this research showed generally consistent results in the wider risk communication literature such that fear-provoking climate change scenarios such as CIDs suggests that the level of awareness on vulnerability is important. The anxiety and worry do not necessarily predict greater uptake of protective behaviors. Further study on the behavioral and psychological responses to other anticipated climate change impacts, especially those that represent "new" and unfamiliar hazards, is timely. A study on the integration of 'underlying causes' of vulnerability and adaptive capacity in CIDs impact assessments rather than only focusing on adaptive capacity and technical measures is recommended.

\section{REFERENCES}

[1] FAO, The State of Food Insecurity in the World: How does International Price Volatility affect Domestic Economies and Food? Rome, Italy: FAO, 2011.

[2] J. R. Porter et al., "Food Security and Food Production Systems," in Climate Change 2014: Impacts, Adaptation, and Vulnerability. Part A: Global and Sectoral Aspects. Contribution of Working Group II to the Fifth Assessment Report of the Intergovernmental Panel on Climate Change, C. B. Field et al., Eds. Cambridge, United Kingdom and New York, USA: Cambridge University Press, 2014, pp. 485-533.

[3] V. Thomas, J. R. G. Albert, and R. T. Perez, "Climate-Related Disasters in Asia and the Pacific,” ADB Economics Working Paper Series No. 358, July 2013. Metro Manila, Philippines: Asian Development Bank: Metro Manila, 2013.

[4] V. Thomas and R. Lopez, "Global Increase in Climate-Related Disasters,” ADB Economics Working Paper Series No. 466, November
2015. Metro Manila, Philippines: Asian Development Bank: Metro Manila, 2015.

[5] N. Kim, "How Much More Exposed are the Poor to Natural Disasters? Global and Regional Measurement,” Disasters, vol. 36, no. 2, pp. 195211, 2012.

[6] W. Ali, "Climate Change and Livelihoods: The Vulnerability Context," A Discussion Paper on Environment and Energy. Poverty and Sustainable Development Unit, United Nations Development Programme in Yemen, December 2013.

[7] H. M. Füssel, "Vulnerability: A Generally Applicable Conceptual Framework for Climate Change Research,” Glob. Environment. Change, vol. 17, no. 2, pp. 155-167, 2007.

[8] K. Dow, "Exploring Differences in Our Common Future(s): The Meaning of Vulnerability to Global Environmental Change,” Geoforum, vol. 23, pp. 417-436, 1992.

[9] S. L. Cutter, B. J. Boruff, and W. Shirley, "Social Vulnerability to Environmental Hazards,” Soc. Sci. Quart., vol. 84, no. 2, pp. 242-261, 2003.

[10] K. Katic, Social Vulnerability Assessment Tools for Climate Change and DRR Programming: A Guide to Practitioners. Istanbul, Turkey: United Nations Development Programme, 2017.

[11] L. Lundgren and A. Jonsson, “Assessment of Social Vulnerability: A Literature Review of Vulnerability Related To Climate Change and Natural Hazards," Centre for Climate Science and Policy Research (CSPR) Briefing No. 9. Norrköping, Sweden: Linköping University, 2012.

[12] G. Oulahen, L. Mortsch, K. Tang, and D. Harford, "Unequa Vulnerability to Flood Hazards: 'Ground Truthing' a Social Vulnerability Index of Five Municipalities in Metro Vancouver, Canada,” Ann. of the Assoc. of Americ. Geograph., vol. 105, no. 3, pp. 473-495, 2015.

[13] C. Kuhlicke, A. Scolobig, S. Tapsell, A. Steinführer, and B. De Marchi, "Contextualizing Social Vulnerability: Findings from Case Studies across Europe,” Natural Hazards, vol. 58, no. 2, pp. 789-810, 2011.

[14] Wu et al., "Application of Social Vulnerability Indicators to Climate Change for the Southwest Coastal Areas of Taiwan.” Sustainability, vol. 8, p. 1270, 2016. DOI: 10.3390/su8121270.

[15] A. Unlu, N. Kapucu, and B. Sahin, "Disaster and crisis management in Turkey: a need for a unified crisis management system,” Disast. Prevent. and Manage., vol. 19, no. 2, pp. 155-174, 2010.

[16] T. Moore and R. Lakha, Tolley's Handbook of Disaster and Emergency Management: Principles and Practice, Croydon: Lexis Nexis, 2004.

[17] C. Pearson and I. Mitroff, "From crisis prone to crisis prepared: a framework for crisis management,” Acad. of Manage. Exec., vol. 7, no. 1, pp. 48-59, 1993.

[18] J. Wilks and S. Moore, Tourism Risk Management for the Asia Pacific Region: An Authoritative Guide for Managing Crises and Disasters. Gold Coast Campus, Griffith University, Queensland, 2003.

[19] I. Shaluf, “Technological disaster stages and management,” Disast. Prevent. and Manage., vol. 17, no. 1, pp. 114-126, 2008.

[20] A. Carmeli and J. Schaubroeck, "Organisational crisis-preparedness: the importance of learning from failures,” Long Range Plan., vol. 41, no. 2, pp. 177-196, 2008.

[21] D. Childs and S. Dietrich, Contingency Planning and Disaster Recovery: A Small Business Guide. Hoboken, NJ: John Wiley \& Sons, 2001. 